\title{
CONTINUIDADES Y DISCONTINUIDADES DE LA VIOLENCIA POLIITICA EN LA TRANSICIÓN A LA DEMOCRACIA EN CHILE 1
}

\section{Continuities and discontinuities of political violence in the transition to democracy in Chile}

\author{
Isabel Piper Shafir* \\ Margarita María Vélez-Maya \\ Universidad de Chile (Chile)
}

\section{Palabras clave}

Memoria colectiva Violencia política Transición política Chile

\section{Keywords}

Collective memory Political violence Political transition Chile
RESUMEN: Este artículo es una reflexión sobre la violencia política en la transición chilena, realizado a partir del diálogo con siete narrativas en las que se abordan las memorias construidas por activistas que la ejercieron durante ese período. Tomando como punto de partida los conocimientos producidos por las y los activistas, por medio del método de las "producciones narrativas», surgen dos ejes de análisis: las reconfiguraciones de las prácticas, sentidos y posibilidades de las violencias para la lucha social en la democracia postdictatorial y las continuidades de la violencia política estatal. Se concluye que la transición política chilena se constituye en un dispositivo de pacificación de la sociedad, en el que se crean instituciones, leyes y discursos que deslegitiman, persiguen y estigmatizan el uso de la violencia política como forma de lucha, mientras que se legitima la violencia política de Estado, dirigida principalmente a quienes representan un riesgo para el mantenimiento del nuevo orden.

ABSTRACT: This article reflects on political violence in the Chilean transition based on a dialogue with seven narratives that address the memories built by activists who exercised it during that period. Taking the knowledge produced by activists, produced through the method of "narrative productions", as a starting point, two axes of analysis emerge: the reconfigurations of the practices, meanings, and possibilities of violence for struggle in post-dictatorial democracy and the continuations of state political violence. The text concludes that Chilean political transition is conformed as a device for the pacification of society. Such a device creates institutions, laws, and discourses that delegitimize, persecute and stigmatize the use of political violence as a form of struggle, while it legitimizes the State political violence, aimed primarily at those who pose a risk to the maintenance of the new order.

1 Este artículo se ha elaborado en el marco del Proyecto Fondecyt Regular N. 1171568 y con el financiamiento de la Agencia Nacional de Investigación y Desarrollo (ANID) / Programa de Becas / Doctorado Becas Chile / 201821181384. Grupo de Trabajo CLACSO Memorias Colectivas y Prácticas de Resistencia.

* Correspondencia a / Correspondence to: Isabel Piper Shafir. Universidad de Chile, Departamento de Psicología, Facultad de Ciencias Sociales. Calle Av. Ignacio Carrera Pinto 1045. Comuna de Ñuñoa (Santiago de Chile) - ipiper@uchile.cl - http://orcid.org/0000-0001-6795-2573.

Cómo citar / How to cite: Piper Shafir, Isabel; Vélez-Maya, Margarita María (2021). «Continuidades y discontinuidades de la violencia política en la transición a la democracia en Chile». Papeles del CEIC, vol. 2021/1, papel 243, 1-15. (http://dx.doi.org/10.1387/pceic.21912).

Fecha de recepción: julio, 2020 / Fecha aceptación: octubre, 2020.

ISSN 1695-6494 / CC 2021 UPV/EHU 
En octubre de 2019 se desarrolla en Chile un levantamiento social en contra de las condiciones sociales, políticas y económicas del país. Aunque los descontentos expresados por las manifestaciones que se extienden a lo largo del territorio son múltiples y diversos, muchos de ellos se refieren directamente al proceso de transición a la democracia. Un ejemplo es el slogan utilizado: "No son 30 pesos sino 30 años», haciendo referencia al alza del pasaje de metro que propició la primera ola de protestas, y al mismo tiempo señalando los «30 años» de democracia post-dictatorial como uno de los elementos que origina el levantamiento.

Las memorias de la transición política constituyeron una parte importante de los motivos y motores de las manifestaciones. Estas se refieren a las promesas incumplidas respecto de la democracia, la libertad y la justicia que con ella vendría. En vez de eso, se recuerda como los gobiernos post-dictatoriales fortalecieron un sistema político fuertemente restringido, basado en la Constitución política elaborada bajo el mandato de Augusto Pinochet. El levantamiento es contra una democracia transicional tutelada por fuerzas armadas y policiales que actúan sobre la disidencia defendiendo el modelo económico y el orden social heredado por la dictadura, interviniendo frente a cualquier posible amenaza con el uso de una violencia que es amparada por un amplio margen de impunidad que le otorga la ley y le garantizan las autoridades. "No son 30 pesos sino 30 años», dicen las y los manifestantes anclando su descontento en las memorias críticas e indignadas de la post-dictadura.

Si bien las voces críticas con el pacto transicional, así como con el modelo que este fortaleció y profundizó, se alzaron con fuerza y se hicieron visibles a partir del levantamiento de octubre, no son algo nuevo. El debate respecto del camino de salida de la dictadura se inició poco después del golpe de Estado de 1973. En el año 1977, Augusto Pinochet ya estaba dando a conocer sus reglas del juego para construir una institucionalidad, un programa político y un itinerario, que incluye la entrada en vigor de una nueva constitución y la realización de un plebiscito -en 1988- en el que se votaría SI o NO a su continuidad como jefe del gobierno. En todo ese período la oposición discute respecto al carácter de la transición. Mientras algunos sectores defienden la idea de plegarse al pacto propuesto por la dictadura, otros sostienen que esta debe ser derrocada mediante un proceso de movilización popular para lo que sería legítimo usar diversas formas de lucha.

En los años setenta y ochenta, la lucha armada cuenta con la legitimidad y el apoyo de una parte importante de la oposición a la dictadura, y el camino de derrocar a Pinochet es para algunos sectores de la izquierda la única posibilidad real de cambiar el sistema económico y político impuesto por la fuerza. En septiembre de 1986, el Frente Patriótico Manuel Rodríguez (aparato armado del Partido Comunista, PC) atenta contra la vida de Pinochet. Su fracaso acaba por resolver el debate, y lleva a la mayoría de las fuerzas políticas (incluso al PC) a participar del plebiscito de 1988 propuesto por el dictador.

El triunfo de la opción NO en el plebiscito de 1988 deriva en la realización de elecciones presidenciales un año después. En marzo de 1990 asume como presidente Patricio Aylwin, en representación de la entonces llamada Concertación de Partidos por la Democracia. La historia política de Aylwin, militante Demócrata Cristiano y uno de los promotores del Golpe de Estado, es una de las muchas señales de las tensiones con las que se desarrolla tanto la transición como sus gobiernos, cuyo horizonte de modelo social parece estar supeditado a la conservación de la democracia recién recuperada, ejerciendo una importante autocensura respecto de la realización de cambios políticos, económicos y sociales de fondo. 
La transición tiene una vocación fundacional. Instala el inicio del camino hacia un nuevo orden, y lo hace promoviendo ciertas verdades: sobre el pasado, sobre la política y sobre los futuros que son posibles. El conflicto se administra, entre otras cosas, construyendo un régimen de verdad (Follegati, 2019a; 2019b). Es decir, se producen formas y registros que generan una verdad que establece los límites de lo posible y que cambia la forma de enfrentarse a lo político.

Entre esas verdades está el rechazo a la violencia política, construyendo la certeza de que violencia y democracia son antagónicas. Los discursos de defensa del orden público y la seguridad ciudadana (Jorquera-Álvarez, 2019), así como la certeza de que la democracia debe ser defendida ante cualquier amenaza, le dan sustento al rechazo de cualquier forma de violencia insurgente. Para garantizar la pacificación de la sociedad (Rosas, 2010), se crean leyes especiales $^{2}$, cárceles de alta seguridad ${ }^{3}$ e instituciones dedicadas a enfrentar acciones calificadas como subversivas ${ }^{4}$, legitimando de esta manera prácticas que pocos años antes eran consideradas represivas. Mientras las violencias políticas de Estado adquieren formas legítimas, las violencias utilizadas como medio de lucha político-social giran en un sentido opuesto.

En dictadura el uso de la violencia como forma de resistencia cuenta con una cierta simpatía legitimadora por parte de las bases sociales, pero una vez comenzada la transición, pasa a considerarse una práctica injustificada en el contexto democrático (Piper et al., 2020). Se produce un proceso de deslegitimación de esta y de la protesta social —en especial la más radical- al ser considerada una fuente de conflicto y riesgo para la gobernabilidad y la consolidación democrática (Jara, 2013). Sin embargo, pese a las persecuciones, encarcelamientos, destierros y asesinatos, existen diversos grupos y movimientos que, desde una postura crítica a la transición, resisten ante un sistema político que es entendido como una continuidad de la dictadura.

Este artículo se desarrolla a partir de los resultados obtenidos en la investigación «Memorias de la violencia política en la transición a la democracia en Chile construida por activistas que la ejercieron durante dicho periodo" ${ }^{5}$. Esta se propuso comprender las memorias colectivas que activistas que ejercieron la violencia política durante la transición a la democracia en Chile (1988-1998) construyen sobre ese ejercicio. Entre los interrogantes que se plantean, y que son analizados en este artículo, están los significados que las y los activistas entrevistados/as construyen sobre los ejercicios de las violencias políticas en el período. Se trata de personas que continuaron con la lucha armada aún después de la recuperación de la democracia, y/o de quienes, sin haber militado en los ochenta, se incorporaron a un activismo - que por su radicalidad - se quedó fuera de la nueva institucionalidad democrática y fuera de los nuevos campos de legitimidad. Estos sujetos encarnan el tránsito hacia una nueva forma de acción política cuya relación con la violencia es incierta. No se trata de la violencia revolucionaria de los años setenta ni de aquella que resiste a los aparatos represivos durante los años ochenta, sino de una violencia que transita en formas, sentidos y objetivos. Estos sujetos sig-

\footnotetext{
Como la ley Antiterrorista, Ley de Seguridad del Estado, Ley de Control de Armas y el Código de Justicia Militar. Entre las cuales está la Unidad Especial de Alta Seguridad creada por el Decreto 353 del año 1994.

Como el organismo conocido como "La Oficina» (Consejo Coordinador de Seguridad Pública cuyo objetivo era asesorar, proponer y coordinar las políticas de seguridad pública vinculadas al ámbito terrorista -Decreto 363 , 1991-); y diversas unidades especiales contrainsurgentes de la Policía Civil, por ejemplo, la Brigada de Inteligencia Policial (BIP), la Brigada de Investigaciones Policiales Especiales (BIPE) y las Comisarías Investigadoras de Asaltos (CINA) entre otras.

5 Proyecto Fondecyt Regular N. 171568, desarrollado entre 2017 y 2020 en el marco del programa Psicología Social de la Memoria. Sus investigadoras/es fueron: Isabel Piper Shafir (Responsable), Roberto Fernández, Caterine Galaz, Tamara Jorquera y Javiera Ramos. Margarita Vélez-Maya realiza una tesis asociada a los objetivos del proyecto.
} 
nifican el proceso de transición a la democracia desde los márgenes de la política y la institucionalidad transicional, constituyéndose en constructoras/es de memorias subalternas que, por su cercanía con la violencia política, son actores y actrices privilegiados para comprender sus continuidades y discontinuidades (Piper et al., 2020).

Este artículo se construye a partir de un diálogo con siete "producciones narrativas» (Biglia y Bonet, 2009; Pujol y Montenegro, 2013) sobre la experiencia de militancia y su relación con las violencias ${ }^{6}$ en el contexto de la transición. Estas se construyen a partir de sesiones de trabajo en las que investigadoras/es y participantes reflexionan conjuntamente sobre el fenómeno, elaborando a partir de ello un texto que es una memoria de estas y estos últimos. Se trata de un ejercicio de construcción de recuerdos en el que las experiencias del pasado son significadas y explicadas con categorías analíticas disponibles actualmente (Piper y Montenegro, 2017).

\section{METODOLOGÍA}

Entendemos por memoria colectiva aquel proceso y producto social a través del cual se construyen significados sobre el pasado (Halbwachs, 2004a [1950] y 2004b [1925]; Piper, Fernández e Íñiguez, 2013; Vázquez, 2001). La memoria es siempre una acción del presente, históricamente situada, que se realiza en el marco de relaciones de poder específicas a través de recursos lingüísticos disponibles en la colectividad (Halbwachs 2004a [1950]).

Es importante destacar que el campo de la memoria colectiva en Chile se ha centrado en el recuerdo de la dictadura y la violencia política como una característica que la distingue, construyendo una versión hegemónica para la que la violencia habria cesado a partir del inicio de la transición, y los años noventa habrian estado marcados por una fuerte apatía y falta de politización. Es en ese contexto de silencio sobre los activismos del periodo que las y los participantes relatan experiencias sobre las que no suelen hablar y aportan informaciones e interpretaciones sobre un pasado desconocido para muchas/os. También es importante señalar que mientras se construyeron las producciones narrativas ocurrió el levantamiento social de octubre de 2019 en Chile, interpelando a las y los participantes a vincular sus experiencias de lucha en transición con las actuales, analizando el pasado a la luz de los acontecimientos del presente.

El método de producciones narrativas se desarrolla a partir de la noción de conocimientos situados de Donna Haraway (1995 [1991]), que postula que todo conocimiento se produce desde una mirada localizada y parcial, que nunca genera verdades sobre el fenómeno (en nuestro caso el pasado). También plantea la importancia de las conexiones parciales entre posiciones diferentes con el fin de tensionar, transformar y cuestionar significados presentes en el cuerpo social (Piper y Montenegro, 2017). En el proceso de realización de las producciones narrativas se articulan las visiones de las y los investigadores con aquellas de las y los participantes. Ello crea un contexto para la aparición de nuevos significados, sugiriendo novedosas formas narrativas para abordar el tema que permiten repensar y redefinir las ideas que conforman los aparatos político conceptuales dominantes en torno a las violencias en la transición en Chile.

6 Hablamos de violencias en plural pues estas se dan en diversidad de formas, tanto en sus ejercicios por parte del Estado como en sus formas insurgentes. 
El artefacto metodológico crea un espacio de diálogo orientado a la generación de un producto - una narrativa - que, en este caso, permite comprender la construcción conjunta de significados sobre el pasado (Clandinin y Connelly, 2000). Se trata de un texto que es co-participado, dada la relación de investigación entre diferentes posiciones, y también en un sentido más amplio, en términos responsivos respecto del contexto social en el que se inserta. En este sentido, siguiendo a Bajtin (1982), se entiende el lenguaje en clave dialógica, como un proceso relacional, abierto y en constante mutación, de modo que quien enuncia está situado en relación con diferentes géneros de habla, participando en el flujo de diversas acciones discursivas entrelazadas e interdependientes (Piper y Montenegro, 2017).

Cada Producción Narrativa constituye un texto de autoría de el o la participante, y todos ellos están en vías de ser publicados. El proceso de textualización, vigilado y corregido por su autor/a, garantiza la agencia de las y los participantes, quienes pueden modificar el texto, cambiarlo, o incluso revertir lo dicho en función de sus intereses (Pujol y Montenegro, 2013). Las producciones narrativas resultan de una serie de encuentros entre investigadoras/es y participantes (en nuestro caso fueron tres encuentros), emergiendo como significados construidos desde posiciones situadas. Para Schöngut y Pujol (2015) estos deben ser considerados como visiones válidas, que no representan rasgos esenciales de los sujetos que hablan, su posición o experiencia, sino más bien, «siguiendo la metáfora de la difracción de Haraway (1999), producir comprensiones y explicaciones sobre los fenómenos que puedan refutar, diversificar y complejizar los discursos dominantes sobre el tema» (Piper y Montenegro, 2017: 100).

En nuestro caso, cada una de las producciones narrativas construye un relato sobre el pasado que puede ser considerado en el mismo estatus de aquel construido por un/a historiador/a. Es por eso que no son tratados como testimonios a analizar, sino como teorias (sobre transición y violencias políticas en Chile) construidas a partir de la experiencia y con las que dialogamos desde nuestra posición de investigadoras. No son analizadas como datos o representaciones del pasado, sino como hacemos con cualquier texto teórico (Pujol y Montenegro, 2013) que consideramos en nuestras reflexiones sobre el tema, es decir, como un análisis sobre el pasado.

Las producciones narrativas construidas en la investigación (en adelante también, PN) y con las que establecemos un diálogo, son las siguientes:

\begin{tabular}{|l|l|}
\hline \multicolumn{1}{|c|}{ Título PN } & \multicolumn{1}{c|}{ Autor/a ${ }^{7}$} \\
\hline «Biografía de una generación en tránsito» & Chapa \\
\hline «La transición fue cambiarse a una casa vieja con muebles usados» & Víctor Gómez \\
\hline «En los noventa luchamos bailando» & Francisca Fernández \\
\hline «Yo soy la que grita» & Juana \\
\hline «De la lucha armada al trabajo social: asumir la derrota y reconstruir» & Néstor \\
\hline $\begin{array}{l}\text { «Seguir luchando en transición: El salto de luchar contra un dictador a la lu- } \\
\text { cha contra un modelo» }\end{array}$ & Doris Ojeda \\
\hline «La lucha callejera y el anarquismo en el desierto de los noventa» & S.N. \\
\hline
\end{tabular}

7 En algunos casos la autoría se designa con un pseudónimo que fue establecido por el o la participante. 


\section{RECONFIGURACIONES DE LAS VIOLENCIAS POLITIICAS EN LA DEMOCRACIA POST-DICTATORIAL}

\subsection{Violencia política como medio de lucha político-social}

Muchas y muchos activistas se insertan en la institucionalidad política que construye la transición y continúan con la hoja de ruta establecida por la Constitución política de 1980. El plebiscito de 1988, las elecciones que le siguen en 1989 y el cambio al gobierno civil en 1990, constituyen en conjunto un hito en las memorias hegemónicas que lo presentan como un gran cambio, una "fractura" con el pasado oscuro de la dictadura, que es lo que esas memorias se proponen recordar. Sin embargo, el pacto transicional tiene detractoras/es que señalan, entre otras cosas, las continuidades del modelo social, económico y cultural de la dictadura, así como de la violencia política proveniente del Estado.

Durante los primeros años de la transición la lucha armada desarrollada durante la dictadura continúa, aunque con menor fuerza, poder de acción y legitimación social. Durante ese período, las tres Organizaciones Político Militares (OPM) que resistieron a la dictadura continúan operando: algunas fracciones del Movimiento de Izquierda Revolucionaria (MIR, principalmente el MIR-EGP, Ejército Guerrillero de los Pobres), y del Frente Patriótico Manuel Rodríguez (principalmente el FPMR-Autónomo) así como el Movimiento Juvenil Lautaro (Piper et al., 2020; Rosas, 2010). En el año 1994 (aproximadamente) estas organizaciones dejan de realizar acciones de envergadura pues sus militantes se encuentran en su mayoría presas/os, en el exilio o han sido asesinadas/os. Es importante señalar, que según lo expresado por las y los autores de las PN (Chapa, 2020; Gómez, 2020; Néstor, 2020; S.N., 2020), estas dejan de operar no porque sus integrantes decidan abandonar la lucha armada, sino porque sus estructuras y células son desarticuladas por los servicios de inteligencia de la transición.

Aunque este es un período de derrota de las OPM, al mismo tiempo los es de construcción de otras formas de organización y activismo. Quienes forman parte de las OPM y siguen militando ven la necesidad de reinventarse, por lo que a la par de ese proceso de desarticulación, se van gestando otras formas de lucha, hacia las que transitan paulatinamente algunas/ os activistas. Así, a lo largo de los noventa se crean múltiples y diversos "Colectivos Organizados» (CO), caracterizados por ser agrupaciones pequeñas, de corta duración, precarias, no partidistas, convocadas para reivindicar luchas temáticas específicas (estudiantiles, anarquistas, poblacionales, sindicales o indígenas, a las que se van incorporando otros temas, como Derechos Humanos, género o medio ambiente) (Piper et al., 2020).

Estos colectivos están motivados por la necesidad de resistir colectivamente en un contexto de persecución, desconfianza y fuerte marginalidad de proyectos políticos revolucionarios. Para Chapa (2020) los colectivos responden a la necesidad de articularse. Aunque mantienen - al menos en sus inicios - una inercia respecto del funcionamiento de las viejas OPM así como una cierta identidad («mirista», "rodriguista» o "lautarista»), buscan romper el aislamiento y la fragmentación provocada por la disolución de esas organizaciones y por la persecución de la que son objeto los activistas radicales. Gómez (2020) sostiene que las y los militantes de expresiones que quedaron fuera de la coalición gobernante derivaron naturalmente a estas otras organizaciones de lucha, cuyo ideal común es el enfrentamiento a un sistema del que sólo cambiaron sus administradores (Gómez, 2020). 
El uso de las armas se va dejando pues no existe en esa generación de militantes una preparación operativa que permita mantener una estructura, ni tampoco condiciones para pasar a la clandestinidad (Chapa, 2020). La capacidad de operación militar de los Colectivos Organizados es muy débil y se limita al uso -en algunos casos y ocasiones- de cócteles molotov, barricadas y eventualmente armas hechizas como estrategia de agitación y propaganda y/o como forma de defensa frente a la represión que proviene de las Fuerzas de Orden y Seguridad. A diferencia de las OPM, sólo usan la violencia con el propósito de resistir a las estrategias de dominación y a las violencias del sistema neoliberal (Fernández, 2020), sin llegar a concebirla como una forma de acceder el poder y/o cambiar las estructuras sociales (Piper et al., 2020). Cambian tanto los objetivos de su uso como las formas de nombrarla. Se deja de hacer referencia a la «lucha armada», usando términos diferentes como por ejemplo "acción directa» o «lucha callejera» sin que se adopte un nombre común.

Las y los autores de las producciones narrativas (Chapa, 2020; Gómez, 2020; Fernández, 2020; Juana, 2020; Néstor, 2020; S.N. 2020; Ojeda, 2020), defienden la existencia de un sustento ético para la continuidad de la lucha armada o de otras formas radicales de resistencia. Parten de la base de que no existen diferencias de fondo entre dictadura y democracia (al menos no en lo que respecta a la democracia post-dictatorial). Se refieren a la democracia transicional como una "dictadura constitucional», es decir, un sistema en el que cambian las figuras que gobiernan, pero no el proyecto de sociedad. Esta seguiria las definiciones y trayectorias establecidas por la constitución de Pinochet. Fernández (2020), afirma que para quienes luchaban, el objetivo de la transición a la democracia era un cambio radical del sistema político, el fin de la constitución de Augusto Pinochet y la creación de una asamblea constituyente para nueva Carta Magna. Sin embargo, lo que ocurrió fue la consolidación de un modelo pensado desde la dictadura.

El tránsito hacia otras formas de acción política implica una resignificación de la violencia como estrategia de lucha, sin embargo, existe continuidad en los principios que la guían. La necesidad ética y política de oponerse al modelo sigue intacta, en la medida en que la transición no sólo no lo pone en cuestión, sino que habría radicalizado y profundizado sus inequidades y violencias. Esto otorga legitimidad a las formas y objetivos de sus luchas, lo que no habría sido comprendido por quienes creyeron en las promesas de la transición. Para Gómez es importante recordar que existía un diagnóstico claro sobre el tipo de sociedad construida transicional y por tanto en la necesidad de situarse desde un lugar de disidencia respecto de ella (2020).

La continuidad de la violencia de Estado es vivida en carne propia por quienes sostuvieron proyectos de activismo insurreccional. Sus organizaciones y sus compañeras y compañeros de militancia fueron perseguidos/as, tomados/as como prisioneros/as en cárceles de alta seguridad, salieron al exilio y/o fueron asesinados/as. Por tanto, la transición es vivida por ellas/ os como un período tan violento como la dictadura, agravado por la falta de apoyo y base social para sus acciones y resguardo de la seguridad.

\subsection{Violencia política de Estado}

Durante la transición se produce una resignificación de las prácticas de la violencia política, tanto de aquella que proviene del Estado como la que es ejercida por sujetos subalternos, es decir, que se encuentran en los márgenes de los lugares hegemónicos. Mientras las primeras adquieren formas legítimas, las segundas pierden el apoyo de las bases sociales que tuvieron 
en dictadura y sufren una progresiva deslegitimación al ser consideradas un riesgo para la gobernabilidad y la consolidación democrática (Piper, 2020).

El proceso mediante el cual las violencias políticas del Estado adquieren legitimidad obedece a diferentes operaciones de poder. Por un lado, la construcción de una estructura normativa e institucional que otorga un marco de legalidad a estas violencias y por otro, una configuración ideológica que las orienta. Podríamos decir que la forma específica que asume el uso de la violencia Estatal en este periodo tiene correspondencia significativa con la forma de organización del poder político, los imaginarios sociales y los valores que se instalan y la hacen aceptable.

Durante la transición se construyen instituciones democráticas que ejercen la represión bajo el alero de un discurso de defensa del orden público (Jorquera-Álvarez, Íñiguez Rueda y Piper Shafir, 2019), de la democracia, la seguridad ciudadana y la libertad individual. Es decir, se construye una institucionalidad que entrega legalidad y legitimidad a la violencia represiva del Estado, instalando la idea de que el orden público y la seguridad ciudadana son derechos fundamentales (Jorquera-Álvarez, 2019). Bajo ese marco discursivo y normativo, las Fuerzas de Orden y Seguridad continúan reprimiendo a las y los disidentes políticos, amparadas en el lugar que les otorga el ser garantes del orden público. Asimismo, los mecanismos represivos y de resguardo de ese orden gravitan en torno a la utilización de la justicia militar contra civiles y la promulgación de leyes como las llamadas Leyes Especiales (Rosas, 2010). Para Gómez (2020) en ese contexto La Oficina juega un papel fundamental en el control de la disidencia, ya que ésta no sólo logra neutralizar a los grupos armados, sino que también busca evitar la articulación de diversos frentes sociales movilizados, infiltrando agentes en las universidades y los movimientos poblacionales. Así argumenta Gómez, que en los noventa se mantuvo una política de inteligencia hacia organizaciones estudiantiles y de derechos humanos, que buscó controlar su accionar y evitar la articulación con las organizaciones político militares que continuaron funcionando (ibídem).

El discurso de la transición criminaliza las expresiones contestatarias, de resistencia o subversión, catalogando a quienes se oponen al pacto transicional como sujetos irracionales, locos y delincuentes, sin más objetivos políticos que causar pánico y temor en la población ${ }^{8}$. Para ellas y ellos sólo cabría un castigo ejemplar, convirtiéndose esta en una medida aceptable y necesaria en el imaginario social. La criminalización, despolitización y estigmatización de la disidencia, contribuye a construir un sujeto "peligroso», que al acompañarse de una narrativa en la que el Estado se presenta como defensor de la población, fortalece su función de «proteger» a la sociedad (Juana, 2020).

La función del Estado, en este contexto, es la de defender el orden restablecido con el regreso de la democracia frente a cualquier expresión de descontento o de rebeldía que lo ponga en cuestión. De acuerdo con Jorquera-Álvarez (2019), una acción o un sujeto se constituye en una amenaza en la medida en que abre la puerta a la desestabilización de ese orden por medio de acciones de distinto tipo, como confrontar o resistir la acción policial en la calle, en desalojos de recintos "tomados», en una huelga laboral, etc., "hasta formar parte de un

8 Este discurso está presente no sólo en las autoridades policiales y de gobierno, sino también en la prensa de la época, lo que se observó en el análisis de prensa del periodo que muestra los mecanismos de deslegitimación del accionar de los grupos armados a través de operaciones discursivas tales como la criminalización, patologización y condena moral (Piper et al., 2020). 
grupo cuya mera existencia pone en cuestión ese orden tranquilo y unificado (como ser mapuche, o durante los primeros años de postdictadura, formar parte de los grupos políticos de izquierda que permanecieron armados)" (ibídem:169).

El resguardo del sistema neoliberal - defendido y fortalecido por el proceso transicional - se logra a partir de la circulación de discursos, creación de instituciones y elaboración de leyes, lo que se operacionaliza de acuerdo a una determinada forma de administración. Es decir, corresponden a una forma de organización en las que se entrecruzan distintas prácticas de gobierno (Foucault, 1991; 2006). Se pone en escena una pugna por la legitimidad de la violencia represiva estatal, para lo que resulta crucial la despolitización de la acción contestataria.

\section{LA TRANSICIÓN POLÍTICA CHILENA COMO DISPOSITIVO DE PACIFICACIÓN}

En Chile la noción de transición es usada para describir la salida pactada de la dictadura militar de Pinochet -entendida como una situación de desestabilización- hacia la democracia -entendida como una situación de normalidad-. Su discurso hegemónico levanta la idea de que esta significó una ruptura respecto al pasado de la dictadura (Thayer, 1998; Salazar y Valderrama, 2000). En este artículo sostenemos, por el contrario, que resulta más bien una operación de continuidad en la que la relación entre dictadura y transición es de anidamiento y no de ruptura.

Como se señaló anteriormente, la transición no se inventa a sí misma, sino que se comienza a gestar durante los primeros años de la dictadura. A comienzo de los ochenta ya existe un discurso político-académico consolidado que imagina y describe formas de «volver a la normalidad». Las publicaciones de intelectuales de oposición al gobierno cívico-militar como las de Brunner (1981), Garretón y Moulian (1983), Garretón, (1983) y Flisfisch (1983) son una muestra de ello. Frente a esto, cabe preguntarse por esa "normalidad" a la cual se esperaba regresar. En 1973, cuando sectores opositores al Gobierno de Allende, entre ellos el partido Demócrata Cristiano, promovieron y apoyaron el golpe de Estado, buscaban que luego de tomarse el poder y "ordenar el país», los militares devolvieran el mando a las elites políticas regresando a la "normalidad" de una democracia liberal representativa. Aunque el cálculo fue equivocado en un sentido temporal, pues recién diecisiete años después estos grupos volvieron a gobernar, mostraron que la "normalidad» recuperada corresponde al sistema político anterior a la Unidad Popular, es decir, antes de que un gobierno revolucionario llegara al poder.

No existe claridad en relación a cuáles son los límites temporales de la transición. Se podría sostener que esta comienza con su diseño teórico (el de la oposición y/o el de la dictadura), con la creación de la Constitución de 1980, con las protestas en esa misma década que pusieron en tensión la estabilidad del régimen, con el Plebiscito de 1988, con las elecciones de 1989 o bien con el traspaso del gobierno a un civil elegido en 1990. Tampoco existe acuerdo respecto de cuándo termina (ni siquiera si aún ha terminado) o hasta dónde llega, pues para poder responder a esa pregunta habría que establecer cuál era su meta y así determinar si es que fue cumplida. Si la meta era la democracia, sería necesario aclarar qué características debería tener esta para poder decir que ya acabó la transición. Esas preguntas (para las cuales existen muchas respuestas distintas e incluso divergentes) llevan a algunas personas a sostener que se trata de un proceso inconcluso en la medida en que no se han resuelto los encla- 
ves autoritarios heredados de la dictadura y amparados en la constitución de 1980 (Fernández, 2020; Garcés, 2010; García, 2006; Gómez, 2020). Existen también otros hitos a los que se hace referencia para marcar el final de la transición, como el asesinato de la militante anarquista Claudia López en 1998 (Chapa; 2020; Fernández, 2020; Néstor; 2020) que constituye para algunas organizaciones la señal de que los proyectos revolucionarios o de resistencia muestran haber sido derrotados.

El escenario transicional supone un movimiento de doble giro: por un lado recuperar el sistema político formal, bajo la calificación de "democracia» y por otro, consolidar el modelo neoliberal instaurado por la dictadura, poniendo en operación los mecanismos para su desarrollo (Rosas, 2004). Para llevar a cabo este proceso, se construyen mecanismos de administración del pasado, de regulación de los conflictos y de la vida social y una racionalidad política. De esta manera se constituye en un dispositivo que conjuga una red de elementos y prácticas que deben ser analizados en su conjunto y en interrelación.

Siguiendo a Foucault (1991), pensamos el dispositivo como un conjunto heterogéneo que incluye discursos, instituciones, leyes, medidas policiales y proposiciones filosóficas. Consiste en la red que se teje entre estos distintos elementos. Los dispositivos tienen siempre una función estratégica concreta, la cual está inscrita en una relación de poder. Como hemos señalado, en la transición chilena se ponen en funcionamiento una serie de estrategias materiales y discursivas cuyo principal objetivo es el establecimiento de un nuevo contrato social que cambia los horizontes utópicos de transformación de la sociedad, instalando la democracia y el orden público como los objetivos prioritarios.

En la transición se promueve la construcción de una narrativa hegemónica sobre el pasado y el presente; se crean y/o implementan leyes de control de la disidencia, como son la ley antiterrorista y la ley de seguridad interior del Estado; se construye una nueva institucionalidad que regula el control de las formas radicales de disidencia: Como el organismo conocido como La Oficina (Consejo Coordinador de Seguridad Pública), y diversas unidades especiales contrainsurgentes de la Policía Civil. La persecución, tortura y asesinato de aquellos grupos políticos que no se pliegan al nuevo pacto es un elemento clave en este contexto; asimismo, se crean instituciones como la Cárcel de Alta Seguridad, pensada especialmente para estas personas. La construcción de dos comisiones de la verdad como tecnologías de producción de verdad (Castillejo, 2014), así como la construcción de una arquitectura discursiva oficial en torno a la reconciliación y el consenso.

Sostenemos que la función estratégica del dispositivo transicional es la de pacificación ${ }^{9}$. Las memorias hegemónicas implementadas como parte de este dispositivo, promueven la construcción de una versión (que se dice crítica del pasado), según la cual la responsabilidad del golpe no es sólo de los militares, si no de la extrema politización y polarización de la sociedad, provocada por la radicalización de algunos sectores ${ }^{10}$. El acento en esos peligros lleva a prio-

9 El historiador Pedro Rosas (2004; 2010) sostiene que la prisión política de la transición es un dispositivo de pacificación, nosotras vamos más allá afirmando que el dispositivo es el conjunto del proceso transicional.

10 En Argentina este debate se desarrolló a propósito de la uteoría de los dos demonios» en la que se buscó equiparar la violencia política de Estado con la violencia armada de las organizaciones guerrilleras (Jelin, 2010). De acuerdo con Acha, en este país se desarrolló un campo de estudios historiográfico en el que se pensó los setenta bajo una matriz reduccionista en la que la lucha armada y la represión estatal se sitúan como eje central y explicativo alrededor del cual analizar el proceso político argentino de aquellos años, considerando que la radicalización de ciertos sectores conllevó al terrorismo de Estado (Acha, 2010). 
rizar los objetivos de orden, paz y estabilidad, desactivando los conflictos como una manera de evitar una "vuelta atrás», o sea un nuevo golpe. Estas memorias hegemónicas buscan asegurar la legitimidad y el futuro del nuevo sistema de gobierno, atribuyendo los errores del pasado a quienes vendrían a ser los responsables de ellos (Huyssen, 2002; Acha, 2010).

En ese contexto, en el que los valores fundamentales son el orden, la seguridad y el bienestar individual, se mantiene la cuestión de qué hacer con quienes se niegan a plegarse al pacto transicional y a ser pacificadas/os, constituyéndose de esta manera en una amenaza a la estabilidad del sistema económico, político y social. La respuesta del Estado es la que ya hemos descrito: la persecución y el exterminio de estos sujetos, ya sea por la vía de la prisión, el exilio o directamente de la muerte (Piper et al., 2020; Rosas, 2010).

\section{A MODO DE CONCLUSIÓN}

El éxito de la transición se basa en un acuerdo que se organiza en torno a la democracia como ethos, como valor en sí mismo (Follegati, 2019b). Esto implica construir una dicotomía absolutizante entre dictadura y democracia, así como una crítica explícita y totalizante a las formas armadas de lucha, aunque no así a la violencia política de Estado, frente a la que hay una tolerancia relacionada con la necesidad de mantener el orden público. En la racionalidad de la transición, la violencia política como forma de lucha no tiene cabida, aunque sí aquella que proviene del Estado.

La estrategia de evitar la politización y desactivar el conflicto va acompañada de la sustitución de horizontes políticos, como los de revolución o transformación del capitalismo, por el de acuerdo democrático. En las memorias hegemónicas del pasado reciente chileno, las luchas radicales y la oposición a la transición prácticamente no existen. Frente a eso, las producciones narrativas nos señalan la importancia política y académica de, por una parte, hacer memoria de esas luchas, y por otra, de comprenderlas. Así, las PN contribuyen a la emergencia o constitución de unas nuevas formas de narrar el pasado. En este artículo, reflexionamos en torno a los análisis que estos actores y actrices hacen sobre sus prácticas, sus motivos, su ética y sus relaciones con las violencias políticas. El uso de estas últimas como estrategia de lucha durante la transición responde a la convicción de que esta fue un montaje que ocultaba la continuidad del modelo contra el que luchaban. Responde a una ética que es necesario comprender, y en torno a la cual reflexionan las producciones narrativas.

Estas personas, que vivieron la transición desde los márgenes, que no se plegaron al pacto, que no se creyeron la promesa y siguieron resistiendo ante un sistema social que perciben intacto, pagaron un precio alto. Fueron perseguidas, apresadas, exiliadas o asesinadas/os. Quedaron fuera de las comisiones de verdad y de las políticas de reparación. No tienen espacio en los lugares de memoria, en los archivos, ni en los museos. Constituyen el lado oscuro de la transición, el que esta ha optado por silenciar mientras construye abierta y sistemáticamente las memorias de la dictadura. Aunque las memorias de las luchas políticas de los noventa no han sido, hasta ahora, algo que se haya construido con sistematicidad, es sin duda una época donde ocurren diversos acontecimientos significativos que están pendientes de reconstruir y comprender. Las PN describen y analizan los usos y posibilidades de la violencia en el contexto transicional, relatando experiencias de lucha y represión que están ausentes de las me- 
morias hegemónicas. Por otro lado, sus reflexiones en torno a las violencias del neoliberalismo, así como de la legitimidad (o no) y de la pertinencia (o no) del uso de la violencia como una estrategia de acción política, nos da luces para comprender lo que vivimos en Chile hoy, desde el levantamiento social del 18 de octubre de 2019.

Por una parte, las PN nos muestran las transformaciones y los tránsitos de la violencia política del Estado durante la transición, que se observan en el despliegue de las fuerzas represivas sobre las/os manifestantes, amedrentando, deteniendo arbitrariamente, torturando, abusando sexualmente, y usando desmedidamente la fuerza para disolver las protestas ${ }^{11}$, así como en la defensa que las/los gobernantes hacen de estas. En el contexto del levantamiento social iniciado en 2019, observamos los mecanismos de criminalización de la protesta, despolitización y estigmatización de la disidencia, gestados durante la transición y descritos por las PN.

Por otro lado, lo que se ha desplegado en las calles y plazas del país no es el aparato armado de un partido, o un movimiento revolucionario que busca acceder al poder político para construir una sociedad distinta, sino una práctica de defensa frontal frente a las violencias del neoliberalismo. Lo que observamos es un actuar coordinado de personas o grupos que realizan un conjunto de acciones creativas y articuladas para defenderse y defender a otras/ os de la violencia policial. No se trata de un movimiento orgánico (al menos por ahora), que posea formación militar previa y que use el contexto de rebelión popular y sus manifestaciones como una plataforma para conseguir sus objetivos, sino de colectivos situacionales cuyo objetivo e identidad se realiza en la resistencia que ejercen. Para poder entender esto, es fundamental conocer y comprender las configuraciones y reconfiguraciones de las militancias radicales y usos de la violencia que ocurren en nuestro país en los años noventa.

6.

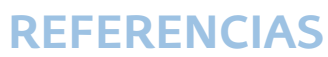

Acha, O. (2010). Dilemas de una violentología argentina: tiempos generacionales e ideologías en el debate sobre la historia reciente. Ponencia presentada en las V Jornadas de Trabajo sobre Historia Reciente. Universidad Nacional de General Sarmiento, 22 al 25 de junio de 2010. https://eltopoblindado.com/

Bajtin, M. (1982). Estética de la creación verbal. México: Siglo XXI.

Biglia, B., y Bonet, J. (2009). La construcción de narrativas como método de investigación psico-social. Prácticas de escritura compartida. Forum: Qualitative Social Research, 10(1). http://www.psiucv.cl/wp-content/uploads/2014/01/2666.pdf

Brunner, J. (1981). La cultura autoritaria en Chile. Santiago: FLACSO.

Castillejo, A. (2014). Imaginación Social del Futuro. Notas para una comisión de la verdad en Colombia. En J.D. Antequera Guzmán (Ed.), Detrás del espejo. Los retos de las comisiones de la verdad (pp. 35-54). Bogotá: Centro de Memoria, Paz y Reconciliación.

11 El saldo de manifestantes afectadas/os, reconocido por el Instituto Nacional de Derechos Humanos - INDHhasta el mes de marzo del año 2020, asciende a 3.838 personas heridas, de ellas 460 con daño ocular, y 10.389 personas privadas de libertad (INDH, 2020). 
Chapa (2020). Producción Narrativa «Biografía de una generación en tránsito». Proyecto Fondecyt Regular N. ${ }^{\circ} \_171568$. Santiago de Chile. Documento no Publicado.

Clandinin, J., y Connelly, M. (2000). Narrative Inquiry: Experience and Story in Qualitative Research. San Francisco: Jossey-Bass.

Fernández, F. (2020). Producción Narrativa «En los noventa luchamos bailando». Proyecto Fondecyt Regular N.﹎_171568. Santiago de Chile. Documento no publicado.

Flisfisch, A. (1983). Coaliciones políticas y transición en Chile: notas exploratorias. FLACSO, Documento de Trabajo, 179.

Follegati, L. (2019a). ¿Postdictadura o transición? Propuestas conceptuales para la historia actual. En J. González Arellano, N. Del Valle Orellana y D. Gálvez González (Eds.), Golpes a la memoria: Escritos sobre la postdictadura chilena (pp. 219-239). Santiago: Tege.

Follegati, L. (2019b). Estrategias analíticas de la Transición a la Democracia: La clave del pasado como perspectiva de futuro. ROSA, 01, 41-61.

Foucault, M. (1991). El juego de Michel Foucault. En Saber y verdad (pp. 127-162). Madrid: Ediciones La Piqueta.

Foucault, M., y Pons, H. (2006). Seguridad, territorio, población: Curso en el Collége de France (1977-1978). Buenos Aires: FCE.

Garcés, M. (2010). Actores y disputas por la memoria en la transición siempre inconclusa. Ayer, 79(3), 147-169.

García, C. (2006). El peso de la memoria en los inicios de la transición a la democracia en Chile (1987-1988). Historia, 2(39), 431-475.

Garretón, M.A. (1983). El proceso político chileno. Santiago: FLACSO.

Garretón, M.A., y Moulian, J. (1983). La Unidad Popular y el conflicto político en Chile. Santiago: FLACSO y LOM ediciones.

Gómez, V. (2020). Producción Narrativa «La transición fue cambiarse a una casa vieja con muebles usados». Proyecto Fondecyt Regular N. ${ }^{\circ}$ 171568. Santiago de Chile. Documento no publicado.

Halbwachs, M. (2004a/1950). La memoria colectiva. Zaragoza: Prensas Universitarias.

Halbwachs, M. (2004b/1925). Los marcos sociales de la memoria. Barcelona: Anthropos.

Haraway, D. (1995). Conocimientos situados: la cuestión científica en el feminismo y el privilegio de la perspectiva parcial. En Ciencia, cyborgs y mujeres. La reinvención de la naturaleza (pp. 313-346). Madrid: Ediciones Cátedra.

Haraway, D. (1999). Las promesas de los monstruos: una política regeneradora para otros inapropiados/bles. Política y Sociedad, 30, 121-163.

Huyssen, A. (2002). En busca del futuro perdido. Cultura y memoria en tiempos de globalización. México: FCE-Instituto Goethe.

Instituto Nacional de Derechos Humanos. (2020). Reporte general de datos sobre violaciones a los derechos humanos. Datos desde 17 de octubre de 2019 e ingresados hasta el 13 de marzo de 2020. https://www.indh.cl/archivo-de-reportes-de-estadisticas/ 
Jara, C. (2013). (Des)Movilización de la sociedad civil en América Latina: Factores tras las trayectorias de participación social. Polis, Revista Latinoamericana, 36, 1-23.

Jelin, E. (2010). Militantes y combatientes en la historia de las memorias: silencios, denuncias y reivindicaciones. En Anuario lucha armada en la Argentina (pp. 70-83). Buenos Aires: Ejercitar La Memoria Editores.

Jorquera-Álvarez, T. (2019). Violencia política de Estado en el Chile postdictatorial (Tesis doctoral inédita). Universitat Autònoma de Barcelona en cotutela con Universidad de Chile, Barcelona.

Jorquera-Álvarez, T., İñiguez Rueda, L., y Piper Shafir, I. (2019). Qué es la seguridad para el Estado chileno: Análisis de discurso 1990-2016. Política y Sociedad, 56(3), 757-777.

Juana (2020). Producción Narrativa "Yo soy la que grita». Proyecto Fondecyt Regular N. ${ }^{\circ} \_171568$. Santiago de Chile. Documento no publicado.

Néstor (2020). Producción Narrativa «De la lucha armada al trabajo social: asumir la derrota y reconstruir». Proyecto Fondecyt Regular N. ${ }^{\circ} \_171568$. Santiago de Chile. Documento no publicado.

Ojeda, D. (2020). Producción Narrativa «Seguir luchando en transición: El salto de luchar contra un dictador a la lucha contra un modelo». Proyecto Fondecyt Regular N. ${ }^{\circ}{ }_{1} 171568$. Santiago de Chile. Documento no publicado.

Piper-Shafir, I. (2020). Nuevas violencias resistentes frente al Chile neoliberal. El Desconcierto. Recuperado de: https://www.eldesconcierto.cl/2020/01/19/nuevas-violenciasresistentes-frente-al-chile-neoliberal/

Piper-Shafir, I., Fernández-Droguett, R., e İñguez-Rueda, L. (2013). Psicología Social de la Memoria: Espacios y Políticas del Recuerdo. Psykhe, 22(2), 19-31.

Piper, I., Fernández, R., Galaz, C., y Jorquera, T. (2020). Informe final Proyecto Fondecyt Regular. Memorias de la violencia política en la transición a la democracia en Chile construida por activistas que la ejercieron durante dicho período. Documento no publicado.

Piper, I., y Montenegro, M. (2017). Ni víctimas, ni héroes, ni arrepentido/as. Reflexiones en torno a la categoría «víctima» desde el activismo político. Revista de Estudios Sociales, 59, 98-109.

Pujol, J., y Montenegro, M. (2013). Producciones Narrativas: una propuesta teórico-práctica para la investigación narrativa. En M. Rodigou Nocetti y H. Paulín (Coords.), Coloquios de investigación cualitativa. Desafios en la investigación como relación social (pp. 15-42). Córdoba: Universidad Nacional de Córdoba.

Rosas, P. (2004). Rebeldia, subversión y prisión política. Crimen y castigo en la transición chilena. Santiago: Editorial LOM.

Rosas, P. (2010). Rebeldía, subversión y prisión politica. Crimen y Castigo en la Transición Chilena 1990-2004. Santiago: Septiembre negro.

Salazar, M., y Valderrama, M. (2000). Dialectos en transición. Santiago: LOM, ARCIS. 
Schöngut, N., y Joan, P. (2015). Relatos metodológicos: difractando experiencias narrativas de investigación. Forum: Qualitative Sozialforschung/Forum: Qualitative Social Research 16(2).

S.N. (2020). Producción Narrativa "La lucha callejera y el anarquismo en el desierto de los noventa». Proyecto Fondecyt Regular N. ${ }^{\circ}{ }^{171568 .}$ Santiago de Chile. Documento no publicado.

Thayer, W. (1998). Borrador sobre la transición. Santiago: Universidad ARSIS.

Vázquez, F. (2001). La memoria como acción social: Relaciones, significados e imaginario. Barcelona: Paidós. 